\title{
Pharmacovigilance Study on Platinum-based Chemotherapeutic Regimens in Oral Cancer Patients: A Prospective Cohort Study
}

\author{
K. MURTI*, K. PANDEY ${ }^{1}$, R. K. KRISHNA, M. K. RASTOGI, M. ALI², V. V. GAHLOT ${ }^{2}$, C. S. LAL ${ }^{3}$ AND P. DAS $^{4}$
}

Department of Pharmacy Practice, National Institute of Pharmaceutical Education and Research, Hajipur-844102, ${ }^{1}$ Department of Clinical Medicine, Rajendra Memorial research institute of Medical Sciences, Patna-800 007, ${ }^{2}$ Department of Oncology, Mahavir Cancer Sansthan and Research Centre, ${ }^{3}$ Department of Biochemistry, ${ }^{4}$ Department of Microbiology, Rajendra Memorial research institute of Medical Sciences, Patna-800 007, India

Murti, et al.: Pharmacovigilance Study on Platinum-based Chemotherapeutic Regimens

\begin{abstract}
Platinum-based chemotherapy is one of the most common therapies employed in oral cancer treatment. This is a prospective cohort study to analyse the pattern and incidence of adverse drug reactions to platinum-based chemotherapeutic regimens in oral cancer patients. Pharmacovigilance studies are still unexplored in oral cancer patients in Bihar, India. Oral cancer patients who received platinum-based cancer chemotherapy were monitored for adverse drug reactions. The collected reports analysed for demographic, causality, preventability and severity of adverse drug reactions. Causality was assessed by the World Health Organization causality assessment scale. Preventability and severity of adverse drug reactions assessed by modified Schumock and Thornton scale, modified Hartwig and Siegel scale, respectively. Incidence rate, relative risk and attributable risk were evaluated among the regimens. Out of 120 patients, $108(90 \%)$ patients were males. One hundred and five patients $(87.5 \%)$ developed a total of 247 adverse drug reactions. World Health Organization Uppsala Monitoring Centre causality scale showed $82 \%$ of adverse drug reactions were "certain", 15\% were "probable" and 3\% were "possible". Modified Hartwig and Siegel severity scale showed $89 \%$ of adverse drug reactions were of "mild" and $11 \%$ were of "moderate" type. Schumock and Thornton preventability scale showed $93 \%$ of adverse drug reactions were "not preventable" and $20 \%$ were "probably preventable". Paclitaxel+carboplatin regimen showed lowest values in terms of adverse drug reactions. Platinum-based chemotherapy was used in the treatment of oral cancer. From this study it is evident that paclitaxel+carboplatin regimen reported least incidence rate of adverse drug reactions among platinum regimens. Incidence rate was more reported in cisplatin regimen.
\end{abstract}

Key words: Adverse drug reactions, platinum-based chemotherapy, oral cancer, pharmacovigilance

Adverse drug reaction is a common phenomenon associated with cancer chemotherapy. According to World Health Organization (WHO) an adverse drug is noxious and unintended, which occurs at doses normally used in man for prophylaxis, diagnosis or therapy of disease or for modification of physiological function excluding failure to accomplish the intended purpose $^{1]}$. ADRs cause serious disability and mortality to patients besides being a burden to the healthcare system $^{[2,3]}$. Pharmacovigilance is a branch of science, which deals with monitoring, detection, assessment, understanding and prevention of $\mathrm{ADRs}^{[4]}$. Oral cancer is a head and neck cancer with cancer growth located in the oral cavity ${ }^{[5]}$. Ninety percent of all oral cancers are squamous cell carcinomas ${ }^{[6]}$. About 135000 reaction $(A D R)$ is defined as a response to a drug which

deaths are reported in the world every year due to oral cancer ${ }^{[7]}$. Amongst the top three types of cancers in the Indian subcontinent, oral cancer accounts for $30 \%$ of all cancers and is a major medical problem ${ }^{[8]}$. National cancer registry programme of the Indian Council of Medical Research reported highest number of oral cancers worldwide with up to 80000 new cases annually ${ }^{[9]}$. Tobacco and alcohol are regarded as the major risk factors for oral cancer ${ }^{[10]}$. Different studies suggest that smokeless tobacco or chewing of tobacco

This is an open access article distributed under the terms of the Creative Commons Attribution-NonCommercial-ShareAlike 3.0 License, which allows others to remix, tweak, and build upon the work non-commercially, as long as the author is credited and the new creations are licensed under the identical terms

Accepted 05 November 2016

Revised 14 October 2016

Received 06 June 2016

*Address for correspondence E-mail: krishnamurti74@yahoo.co.in

November-December 2016

Indian Journal of Pharmaceutical Sciences 
is a major reason for occurrence of oral cancer ${ }^{[11,12]}$. Oral cancer risk is found higher in the population belongs to lower socio-economic class ${ }^{[13]}$.

Platinum-based chemotherapy consisting of either cisplatin or other platinum analogues is combined with other drugs used in treatment of recurrent or metastatic squamous cell carcinoma of oral cavity. The platinumbased chemotherapy along with chemoradiotherapy (radiotherapy plus concurrent chemotherapy) are considered as standard treatment of locally advanced oral cancer treatment ${ }^{[14]}$.

Platinum compounds are associated with different adverse drug reactions and most of it is dose limited ${ }^{[15]}$. Different studies especially done in southern India support this statement ${ }^{[16]}$. Our study is done in the eastern state of Bihar in India, where oral cancer is more prevalent and where these types of studies are limited. Rising costs of patient care, increasing awareness of patients towards the untoward effects of the drugs and the rise in the frequency of cases of litigation against doctors and hospitals have made clinicians, hospital administrators and health care providers aware of the necessity to closely monitor adverse drug reactions ${ }^{[17]}$. This study is mainly focusing on pattern of ADRs occurred due to treatment with different platinum-based chemotherapeutic regimen used in oral cavity cancer. According to our knowledge no pharmacovigilance studies have ever performed in ADRs of platinumbased chemotherapeutic regimen used in oral cavity cancer.

\section{MATERIALS AND METHODS}

The study was approved by Institutional Ethical Committee of Mahavir Cancer Sansthan, Patna, India. This was a prospective observational study carried out for a period of $8 \mathrm{mon}$. Prior to study, detailed informed patient consent was obtained. Oral cancer confirmed patients who received platinum-based chemotherapeutic regimens were included for the study. Baseline data including demographic and chemotherapeutic details were recorded. Case records, drug charts, medical and nursing notes of the patients were reviewed for the presence of adverse drug reactions after each chemo cycles. Laboratory data, discussion with doctors and nursing staff are also used for finding possible ADRs.

The causality relationship of the reported ADRs was analysed using World Health Organization Uppsala Monitoring Centre (WHO UMC) causality assessment scale ${ }^{[18]}$. On the basis of this scale, ADRs were categorized into certain, probable and possible types. The severity of the ADRs was determined using Hartwig and Siegel scale. According to this scale, ADRs were assessed as mild, moderate and severe ${ }^{[19]}$. The modified Schumock and Thornton criteria were used for determining the preventability of the ADRs ${ }^{[20]}$. Three major regimens which were used in the hospital were 5-FU+cisplatin; paclitaxel+carboplatin; cisplatin alone were included in the study. A total of 120 patients were included, 40 patients on each regimen. The statistical data analysis was done using SPSS software package version 16.

\section{RESULTS AND DISCUSSION}

Demographic and clinical characteristics of patients were shown in the Table 1 . Out of 120 patients who were included in the study, 108 (90.0\%) were males. Mean age of patients was $46.24 \pm 11.0$ y $(95 \%$ CI, 44.23-48.23). Most of the patients belonged to the age group $40-60$ y $(58.3 \%)$. Ninety five patients $(79.2 \%)$ had tobacco addiction and 25 (20.8\%) did not. Buccal mucosa $(47.5 \%)$ was the common anatomical subtype of oral cancer observed in the study. According to American Joint Committee on Cancer (AJCC) staging most of the cases belonged to stage IV (84.1\%). Most of the cases belonged to grade 1 keratinizing squamous cell carcinoma (66.0\%). Forty eight $(40.0 \%)$ patients had body mass index (BMI) less than normal, 63 (52.5\%) patients possessed normal BMI, 7 (15.8\%) were overweight and $2(1.7 \%)$ were obese.

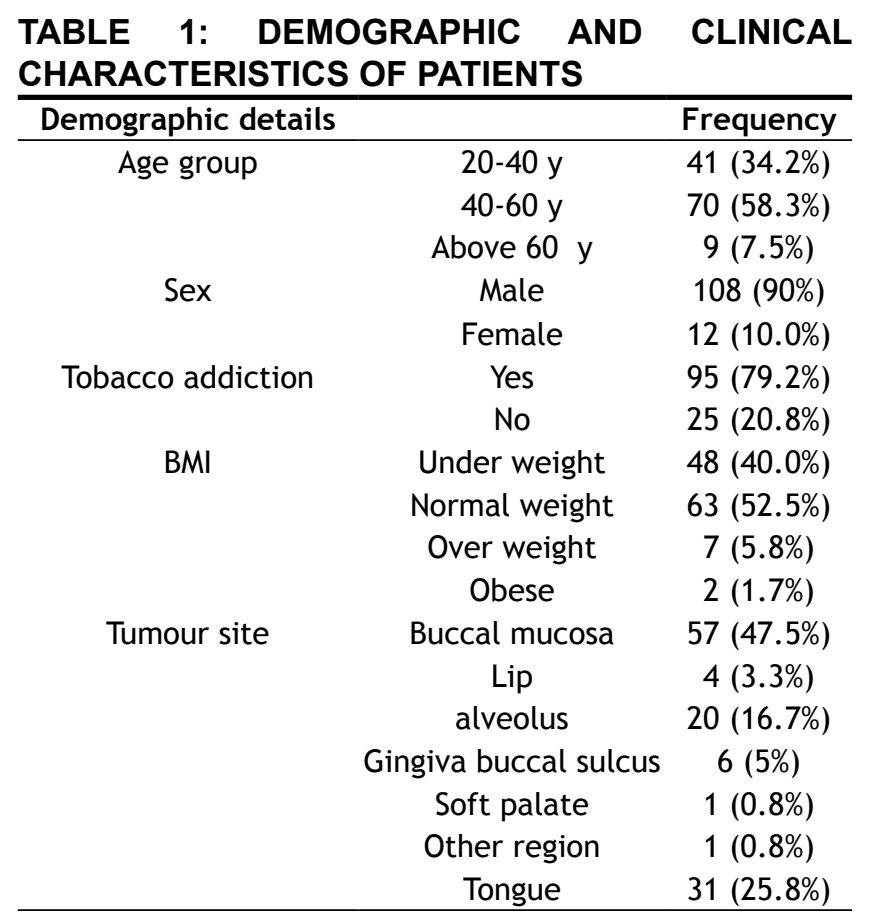


ADR assessment using various scales indicated out of 120 patients who received platinum-based chemotherapy 105 patients $(87.5 \%)$ developed a total of 247 ADRs. According to WHO UMC causality scale, $82 \%$ of ADRs were "certain", $15.0 \%$ were "probable" and $3.0 \%$ were "possible" (fig. 1). According to modified Hartwig and Siegel severity scale, $89.0 \%$ of ADRs were of "mild" and $11.0 \%$ were "moderate" type (fig. 1). According to Schumock and Thornton preventability scale, 93.0\% ADRs were "not preventable" and 20.0\% were found to be "probably preventable" (fig. 1). Most number of ADRs were reported in cisplatin regimen (125) followed by 5-FU+cisplatin (79) (Table 3). Most ADRs were reported in the haematological system $(74.8 \%)$ followed by skin $(8.9 \%)$ and renal system (6.3\%, Table 2).

From Table 3 it can be concluded that the incidence rate was comparable in the case of cisplatin regimen and 5-FU+cisplatin regimen. Relative risk and attributable risk is highest in cisplatin regimen compared to other two regimens. Paclitaxel+carboplatin regimen showed the lowest values among the three regimens in ADRs incidence rate, relative risk and attributable risk. The chi-square test between regimen and ADR incidence showed a statistically significant association $(\mathrm{P}=0.01)$. Univariate analysis of regimens revealed variance of $32.3 \%$.

Fig. 2 depicted paclitaxel+carboplatin regimen and assessment of the associated ADRs with this regimen. WHO UMC causality assessment of this regimen showed $88.0 \%$ of ADRs were "definite" and $12.0 \%$ were "probable", Hartwig and Siegel severity assessment showed $97.5 \%$ were 'mild' and $2.4 \%$ were of 'moderate' type, Modified Schumock and Thornton

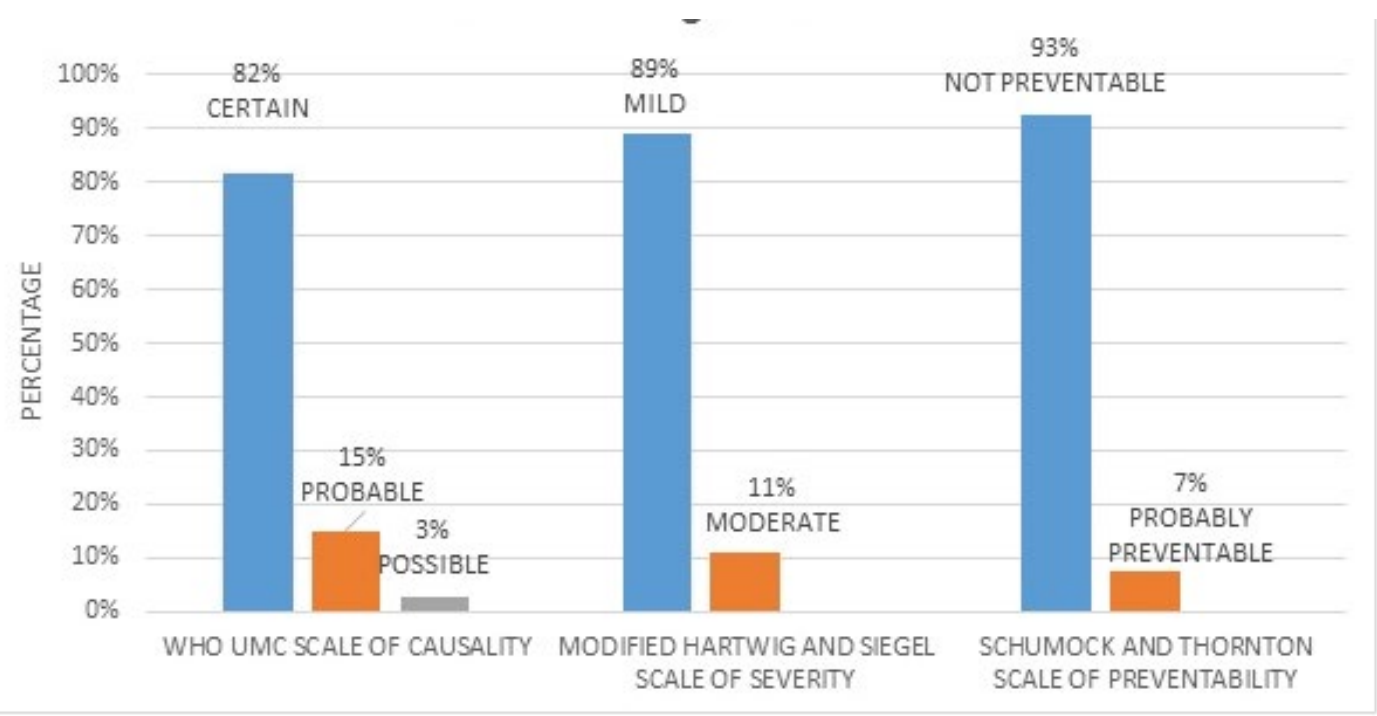

Fig. 1: Causality, severity and preventability assessment of reported ADRs.

\section{TABLE 2: ADRS DISTRIBUTION IN DIFFERENT ORGAN SYSTEM}

\begin{tabular}{lccc}
\multicolumn{1}{c}{ Organ system involved } & ADRs & Frequency & Percentage \\
& Anaemia & 93 & $37.60 \%$ \\
Haematological system (74.8\%) & Leucopenia & 17 & $6.80 \%$ \\
& Thrombocytopenia & 28 & $11.30 \%$ \\
Gastrointestinal system (5.2\%) & Neutropenia & 19 & $7.60 \%$ \\
& Lymphopenia & 28 & $11.30 \%$ \\
& Vomiting & 7 & $2.80 \%$ \\
Respiratory system (1.2\%) & Constipation & 1 & $0.40 \%$ \\
Central nervous system (0.80\%) & Anorexia & 1 & $0.40 \%$ \\
& Gastritis & 4 & $1.60 \%$ \\
Renal system (6.4\%) & Breathlessness & 3 & $1.20 \%$ \\
Skin (8.9\%) & Restlessness & 1 & $0.40 \%$ \\
Musculoskeletal system $\mathbf{( 2 . 4 0 \%}$ & Dizziness & 1 & $0.40 \%$ \\
\hline
\end{tabular}


TABLE 3: ADRs INCIDENCE, RELATIVE RISK AND ATTRIBUTABLE RISK AMONG REGI

\begin{tabular}{lccccccc}
\hline \multicolumn{1}{c}{ Regimen } & $\begin{array}{c}\text { Number } \\
\text { of ADR } \\
\text { reported }\end{array}$ & $\begin{array}{c}\text { Number of cases } \\
\text { reported }(\mathrm{n}=40 \\
\text { in each regimen) }\end{array}$ & $\begin{array}{c}\text { ADRs } \\
\text { incidence } \\
\text { rate }\end{array}$ & $\begin{array}{c}\text { Relative } \\
\text { risk }\end{array}$ & $\begin{array}{c}\text { Attributable } \\
\text { risk }\end{array}$ & $\begin{array}{c}\text { P-value Univariate } \\
\text { analysis }\end{array}$ \\
\hline Cisplatin (with radiation) & 125 & 38 & $36.1 \%$ & 2.78 & $63.1 \%$ & 0.01 & $32.3 \%$ \\
5-FU+Cisplatin & 79 & 37 & $35.2 \%$ & 1.76 & $43.1 \%$ & variance \\
Paclitaxel+Carboplatin & 43 & 30 & $28.5 \%$ & 0.42 & $42.8 \%$ & & \\
\hline
\end{tabular}

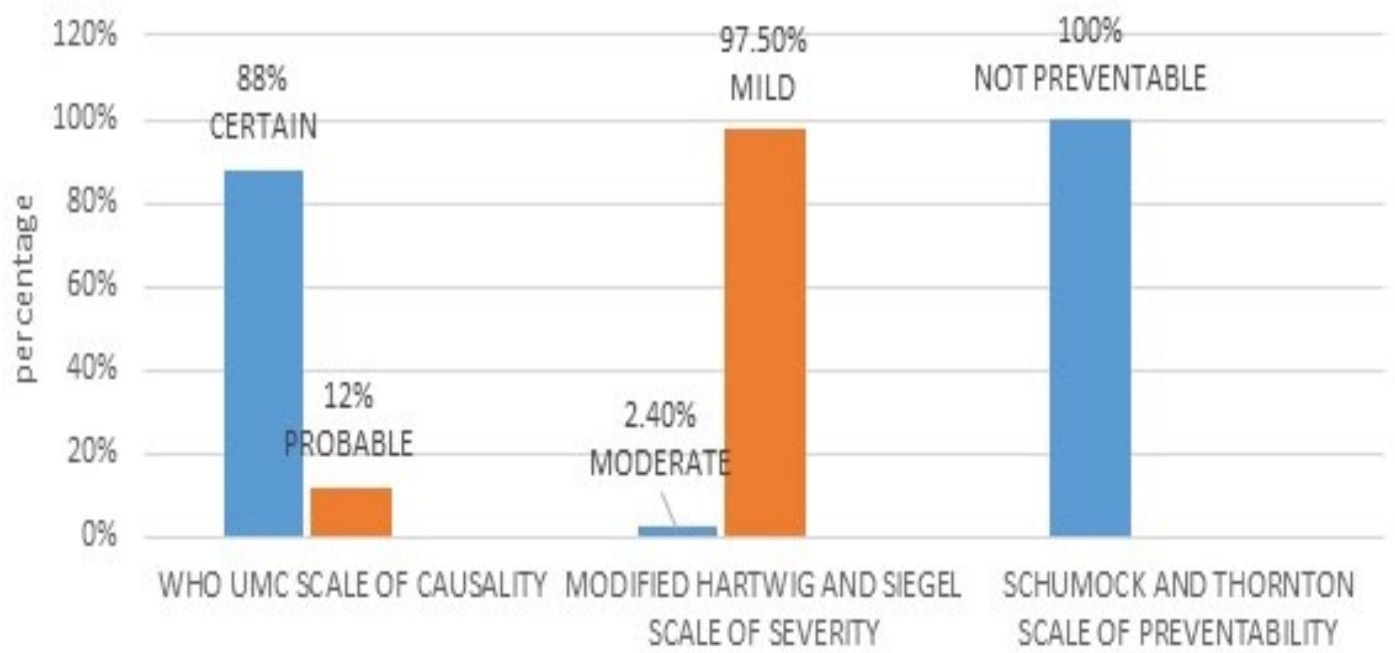

Fig. 2: Causality, severity and preventability assessment of ADRs in paclitaxel+carboplatin regimen.

scales of preventability showed $100 \%$ were "not preventable" ADRs. As shown in Table 4, major type of ADR reported was anaemia followed by leucopenia.

Fig. 3 showed 5-FU+cisplatin regimen and assessment of its ADRs. WHO UMC causality assessment of this regimen showed $92.4 \%$ of ADRs were "definite", $5.0 \%$ were "probable" and $1.26 \%$ are possible, Hartwig and Siegel severity assessment showed $77.2 \%$ are mild and $22.7 \%$ are moderate type, modified Schumock and Thornton scale of preventability showed $98.7 \%$ were "not preventable" and $1.2 \%$ are "probably preventable". From Table 4 it can be concluded that the major type of ADRs reported in the regimen were anaemia followed by neutropenia.

Fig. 4 depicted cisplatin regimen and assessment of its ADRs. WHO UMC causality assessment showed $75.2 \%$ of ADRs were "definite", $5.6 \%$ were "probable" and $19.20 \%$ were 'possible', while Hartwig and Siegel severity assessment showed $94.2 \%$ were 'mild' and $5.7 \%$ were 'moderate' type, modified Schumock and Thornton scale of preventability revealed $92 \%$ were "not preventable" and $8.0 \%$ "probably preventable". The major types of ADRs reported in the regimen were anaemia followed by renal test abnormality as shown in Table 4.

Oral cancer is the sixth most common malignancy reported globally and an important public health problem. Two-thirds of the oral cancer cases are being reported from the developing countries. Approximately, 275000 cases get reported globally every year ${ }^{[21]}$. The platinum compounds were first identified as potential antiproliferative agents in 1965 and cisplatin was the first member of this class, which now has in addition carboplatin and oxaliplatin. Platinum compounds were associated with increased risk of toxicities related to renal, haematological, gastrointestinal and neurological systems. Amifostine, a cytoprotective agent is reported to cause a reduction of renal toxicity associated with repeated administration of cisplatin ${ }^{[22,23]}$. Platinum compounds especially cisplatin is highly emetogenic drug and antiemetic drug should be given to the patient before starting chemotherapy. This study was done exclusively on oral cavity cancer patients and the results from this study may help the physicians while preferring treatment regimens for their patients. Especially when they are considering the particular platinum compound they can choose a regimen with minimum risk for the patients.

The mean age of presentation with oral cancer was $48.8 \mathrm{y}$. This is quite low when compared to study done by Aruna $e t$ $a l .{ }^{[24]}$. The male patients $(90 \%)$ were dominant in the study and this result was similar to the study done by Krishna et $a l^{[25]}$ The most affected anatomical site in our study was 
www.ijpsonline.com

TABLE 4: ADRs DISTRIBUTION AMONG REGIMENS

\begin{tabular}{|c|c|c|c|}
\hline Regimen & ADRs & Frequency & P-value \\
\hline \multirow[t]{14}{*}{ Cisplatin } & Anaemia & $29(11.7 \%)$ & 0.06 \\
\hline & Leucopenia & $10(4 \%)$ & 0.004 \\
\hline & Thrombocytopenia & $14(5.6 \%)$ & 0.179 \\
\hline & Neutropenia & $2(0.8 \%)$ & 0.00 \\
\hline & Lymphopenia & 20 (8.09\%) & 0.000 \\
\hline & Vomiting & $5(2.02 \%)$ & 0.07 \\
\hline & Constipation & $1(0.4 \%)$ & 0.36 \\
\hline & Anorexia & $1(0.4 \%)$ & 0.36 \\
\hline & Gastritis & $4(1.6 \%)$ & 0.01 \\
\hline & Breathlessness & $3(1.21 \%)$ & 0.04 \\
\hline & Dizziness & $1(0.4 \%)$ & 0.36 \\
\hline & Renal function test abnormality & $16(6.4 \%)$ & 0.00 \\
\hline & Alopecia & $14(5.6 \%)$ & 0.002 \\
\hline & Weakness & $5(2.02 \%)$ & 0.02 \\
\hline \multirow[t]{9}{*}{ 5-FU+cisplatin } & Anaemia & $36(14.5 \%)$ & 0.06 \\
\hline & Leucopenia & $7(2.8 \%)$ & 0.004 \\
\hline & Thrombocytopenia & $7(2.8 \%)$ & 0.17 \\
\hline & Neutropenia & $16(6.4 \%)$ & 0.000 \\
\hline & Lymphopenia & $3(1.2 \%)$ & 0.000 \\
\hline & Vomiting & $2(0.8 \%)$ & 0.07 \\
\hline & Alopecia & $6(2.4 \%)$ & 0.002 \\
\hline & Weakness & $1(0.4 \%)$ & 0.02 \\
\hline & Restlessness & $1(0.4 \%)$ & 0.36 \\
\hline \multirow[t]{5}{*}{ Paclitaxel+carboplatin } & Anaemia & $28(11.3 \%)$ & 0.06 \\
\hline & Leucopenia & $7(2.8 \%)$ & 0.004 \\
\hline & Neutropenia & $1(0.4 \%)$ & 0.00 \\
\hline & Lymphopenia & $5(2.02 \%)$ & 0.00 \\
\hline & Alopecia & $2(0.8 \%)$ & 0.002 \\
\hline
\end{tabular}

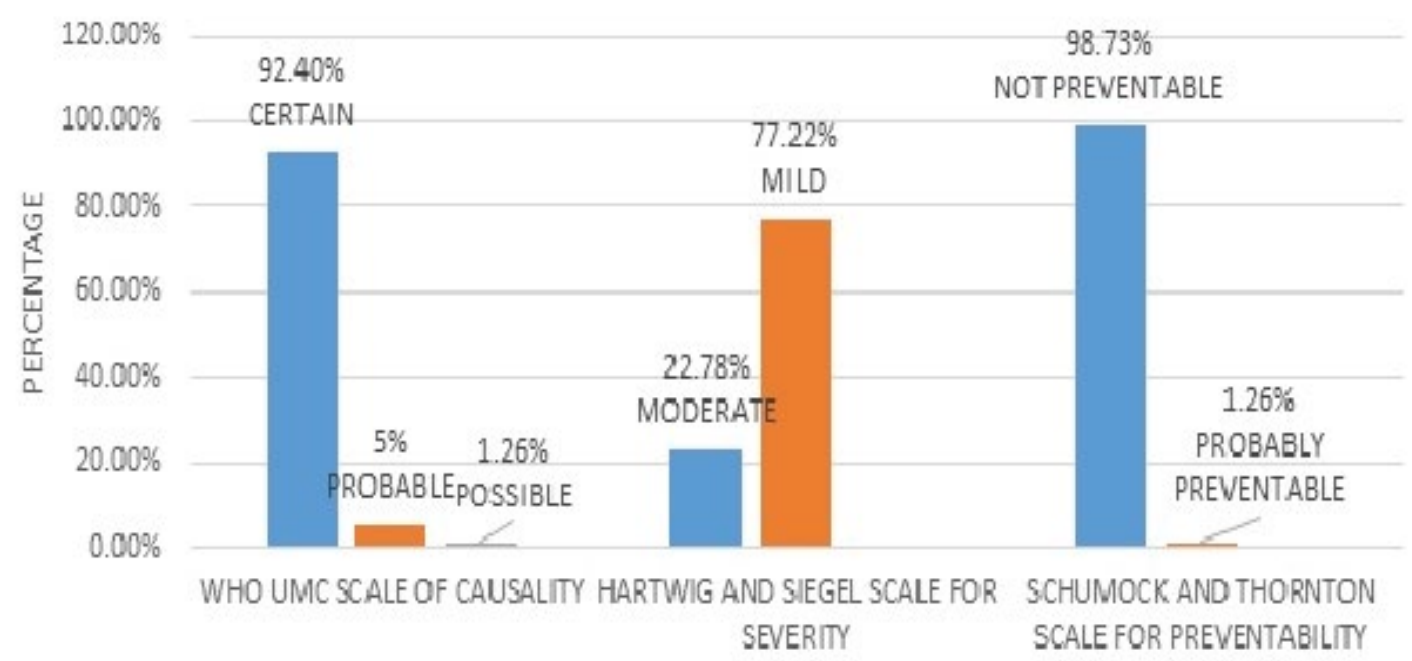

Fig. 3: Causality, severity and preventability assessment of ADRs in 5-FU+cisplatin regimen.

buccal mucosa $(47.5 \%)$. This result is comparable to the findings by Krishna et al. ${ }^{[25]} \mathrm{BMI}$ of majority of patients were found to be normal or below normal. A study conducted by Chatterjee et al., reported that low BMI patients were more vulnerable to ADRs. This study supports the findings of Chatterjee et al. ${ }^{[26]}$ Histological grade of squamous cell carcinoma revealed that majority of the cases were of grade I type (80\%). The result was in agreement with those reported by Krishna et al. ${ }^{[25]}$ Stage III and IV were majority in our study with stage IV was predominant at $84.0 \%$. But findings in our study were in contrast to the study of Krishna et al., where all four stages were almost equally reported ${ }^{[25]}$. According to our study, out of 120 oral cancer patients who received platinum-based chemotherapeutic 


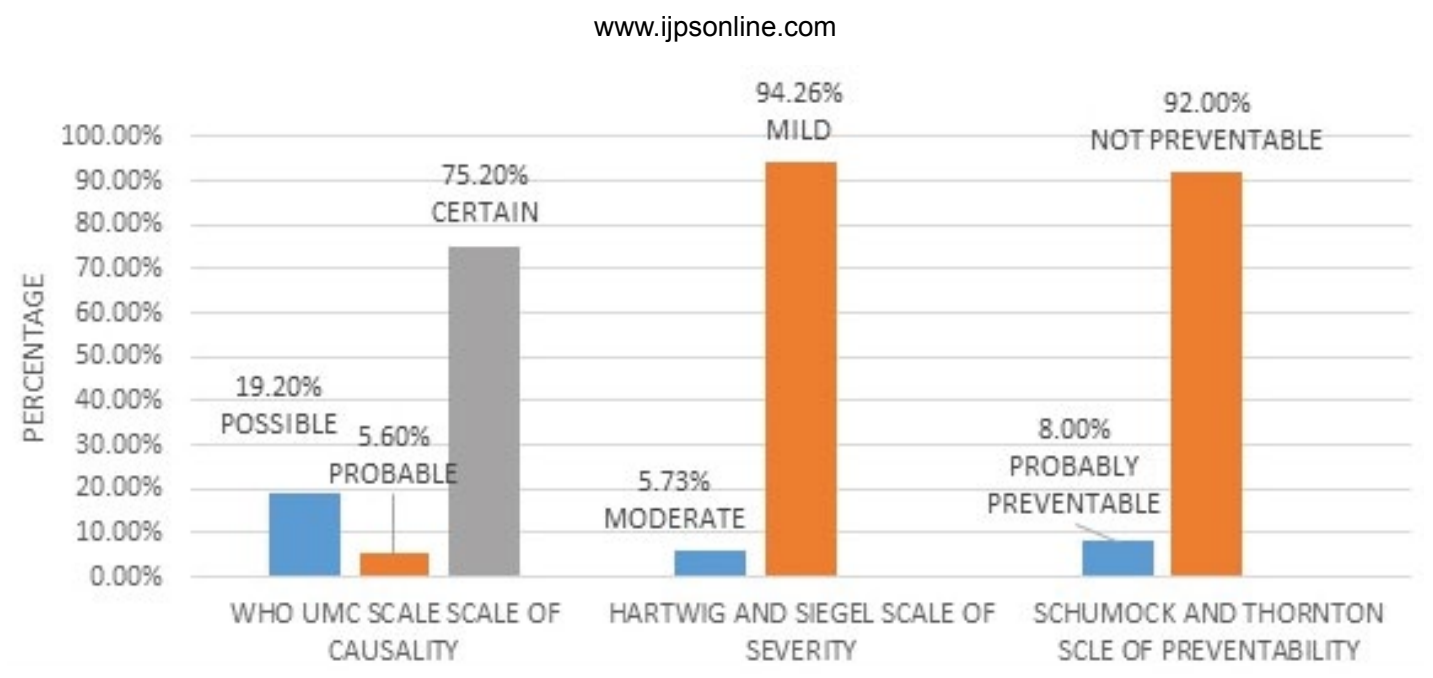

Fig. 4: Causality, severity and preventability assessment of ADRs in cisplatin regimen.

regimens, 105 patients $(87.5 \%)$ reported to have ADRs, which is less than those reported by Surendiran et al. ${ }^{[16]}$ According to WHO UMC causality assessment, most of the ADRs belonged to the category "certain" (82\%), which showed that there is definite relationship with the treatment. According to modified Hartwig and Siegel scale, most of the ADRs belonged to "mild" category $(89.0 \%)$. This result was in agreement with the results reported by Surendiran et al. and another study conducted in a tertiary hospital in Gujarat India ${ }^{[16,27]}$. According to Schumock and Thornton preventability assessment, most of the ADRs belonged to the "not preventable" category $(93.0 \%)$ and similar results have been reported by Surendiran et al. and Khandelwal et $a l .{ }^{[16,28]}$

Cisplatin regimen was reported with most number (125) of ADRs, a result that is in agreement with that reported by Chopra et al. ${ }^{[29]}$ The reason behind this is the effect of radiation along with the chemotherapy. Our study revealed that most of the ADRs were in the haematological system (74.8\%), which is in agreement with that reported by Mallik et al. ${ }^{[30]}$ The univariate analysis between the regimen showed a variance of $32.3 \%$, which revealed that there was a variance in the pattern of ADRs in different regimens. The incident rate, relative risk and attributable risk were found higher in the cisplatin regimen, which revealed higher risk for the occurrence of ADRs when compared to other two regimens.

Chemotherapy has a pivotal role in the improvement of outcome in oncology patients. It is vital to recognize the toxicities related to the antineoplastic drug for better patient safety. Enhanced use of preventive measures and early detection of drug toxicity can reduce the severity of ADRs. Therefore, a comprehensive and effective pharmacovigilance is needed to reduce the burden of ADRs and thereby improving the patient safety.

In conclusion, platinum-based chemotherapy is widely used in the treatment of oral cancer. From this study, it is evident that paclitaxel+carboplatin regimen reported least incidence rate of ADRs among the platinum regimens. Incidence rate was more reported in cisplatin regimen. This is one of those limited studies which were undertaken in the Bihar region, India. Majority of population in this area is socially and economically backward, this directly reflects in their health status. So, it is high time that more pharmacovigilance study especially in different cancer patients should be conducted.

\section{Acknowledgements:}

Authors would like to thank the Staff members of Mahavir Cancer Sansthan, Patna for their help in data collection. Authors also thank the staff members of RMRIMS, Patna, India and NIPER-Hajipur for smooth completion of project. This study was supported by grants from the National Institute of Pharmaceutical Education and Research (NIPER), Hajipur under the aegis of Department of Pharmaceutical, Ministry of Chemicals and Fertilizers, Govt. of India New Delhi, India.

\section{Conflict of interest:}

There is no conflict of Interest within authors.

\section{Financial support and sponsorship:}

Nill.

\section{REFERENCES}

1. WHO, International drug monitoring Role of national centres. 
WHO Technical report series no. 498. Geneva, Switzerland, 1972.

2. Bates DW, Cullen DJ, Laird N, Petersen LA, Small SD, Servi $\mathrm{D}$, et al. Incidence of adverse drug events and potential adverse drug events. Implications for prevention. ADE Prevention Study Group. JAMA 1995;274:29-34.

3. Oshikoya KA, Awobusuyi JO. Perceptions of doctors to adverse drug reaction reporting in a teaching hospital in Lagos, Nigeria. BMC Clin Pharmacol 2009;9:14.

4. Aagaard L, Nielsen LH, Hansen EH. Consumer reporting of adverse drug reactions: a retrospective analysis of the Danish adverse drug reaction database from 2004 to 2006. Drug Saf 2009;32:1067-74.

5. John WW. Oral cancer: diagnosis, management and rehabilitation. New York: Thieme Medical Publishers; 2007.

6. Bagan J, Sarrion G, Jimenez Y. Oral cancer: clinical features. Oral Oncol 2009;46:414-7.

7. Naghavi M, Wang H, Lozano R, Davis A, Liang X, Zhou M, et al. Global, regional and national age-sex specific all-cause and cause-specific mortality for 240 causes of death 19902013: a systematic analysis for the Global Burden of Disease Study. Lancet 2015;385:117-1.

8. Coelho KR. Challenges of the Oral Cancer Burden in India. J Cancer Epidemiol 2012:701932.

9. http://www.ncrpindia.org/Annual_Reports.aspx.

10. Krishna Rao SV, Mejia G, Roberts-Thomson K, Logan R. Epidemiology of oral cancer in Asia in the past decade- an update (2000-2012). Asian Pac J Cancer Prev 2013;14:556777.

11. Madani AH, Dikshit M, Bhaduri D. Risk for oral cancer associated to smoking, smokeless and oral dip products. Indian J Public Health 2012;56:57-60.

12. Muwonge R, Ramadas K, Sankila R, Thara S, Thomas G, Vinoda $\mathrm{J}$, et al. Role of tobacco smoking, chewing, alcohol drinking in the risk of oral cancer in Trivandrum, India: a nested case-control design using incident cancer cases. Oral Oncol 2008;44:446-54.

13. Conway DI, Petticrew M, Marlborough H, Berthiller J, Hashibe M, Macpherson LM. Socioeconomic inequalities and oral cancer risk: a systematic review and meta-analysis of case-control studies. Int J Cancer 2008;122:2811-9.

14. Vermorken JB, Mesia R, Fernando R, Remenar E, Kawecki A, S Rottey, et al. Platinum-based chemotherapy plus cetuximab in head and neck cancer. N Engl J Med 2008;359:1116-27.

15. Amptoulach A, Savaris NT. Neurotoxicity caused by the treatment with platinum analogues. Chemothe Res Pract 2011:843019.

16. Surendiran A, Balamurugan N, Gunaseelan K, Akhtar S, Reddy KS, Adithan C. Adverse drug reaction profile of cisplatin-based chemotherapy regimen in a tertiary care hospital in India: An evaluative study. Indian $\mathrm{J}$ Pharmacol 2010;42:40-3.
17. American Society of Health-System Pharmacists, ASHP guidelines on adverse drug reaction monitoring and reporting. Am J Health-Syst Pharm 1995;55:369-76.

18. The use of the WHO-UMC system for standardized case causality assessment.

19. Hartwig SC, Siegel J, Schneider PJ. Preventability and severity assessment in reporting adverse drug reactions. Am J Hosp Pharm 1992;49:2229-32.

20. Schumock GT, Thornton JP. Focusing on the preventability of adverse drug reactions. Hosp Pharm 1992;27:538.

21. Warnakulasuriya S. Global epidemiology of oral and oropharyngeal cancer. Oral Oncol 2008;44:309-16.

22. Chabner BA, Amrein PC, Druker B, Michaelson MD, Mitsiades CS, Goss PE, et al. Antineoplastic Agents. In: Brunton LL, Lazo JS, Parker KL, editors. Goodman and Gilman's The Pharmacological Basis of Therapeutics. $11^{\text {th }}$ ed. New York: McGraw Hill; 2005. p. 1315-1404.

23. Edward C, Alan CS. Cancer Chemotherapy. In: Katzung GB, Masters BS, Trevor JA, editors. Basic and Clinical Pharmacology. 12 $2^{\text {th }}$ ed. New York: McGraw-Hill Medical; 2012. p. 953-58.

24. Aruna D, Prasad SKVV, Shavi GR, Ariga J, Rajesh G, Krishna M. Retrospective study on risk habits among oral cancer patients in Karnataka Cancer Therapy and Research Institute, Hubli, India. Asian Pacific J Cancer Prev 2011;12:1561-6.

25. Krishna A, Singh RK, Singh S, Verma P, Pal US, Tiwari S. Demographic risk factors, affected anatomical sites and clinicopathological profile for oral squamous cell carcinoma in a North Indian population. Asian Pac J Cancer Prev 2014;15:6755-60.

26. Dattatreyo C, Roy S, Hazra A, Dasgupta P, Ganguly S, Das AK, et al. Variation of adverse drug reaction profile of platinum-based chemotherapy with body mass index in patients with solid tumors: An observational study. Indian J Pharmacol 2014;46:222-4.

27. Yash NG, Krunal CS, Rusva AM, Nisarg DJ, Anil PS, Maganlal VG. Pattern of adverse drug reactions due to cancer chemotherapy in tertiary care teaching hospital in Gujarat. Int J Sci Res 2014;3:333-5.

28. Khandelwal S, Bairy KL, Vidyasagar MS, Chogtu B, Sharan $\mathrm{K}$. Adverse drug reaction profile of cancer patients on chemotherapy in a tertiary care hospital. Int J Pharm Bio Sci 2015;6:233-44.

29. Chopra D, Rehan HS, Sharma V, Mishra R. Chemotherapyinduced adverse drug reactions in oncology patients: A prospective observational survey. Indian $\mathrm{J}$ Med Paediatr Oncol 2016;37:42-6.

30. Mallik S, Palaian S, Ojha P, Mishra P. Pattern of adverse drug reactions due to cancer chemotherapy in a tertiary care teaching hospital in Nepal. Pak J Pharm Sci 2007;20:214-8. 